\title{
Tinjauan Minat Belajar Mahasiswa Olahraga Terhadap Mata Kuliah Gulat di Universitas Islam 45 Bekasi Tatang Iskandar ${ }^{1}$ \\ Islamic University 45 Bekasi, Indonesia Papapt42nk@gmail.com
}

\begin{abstract}
Abstrak
Tujuan dari penelitian ini adalah untuk mengetahui seberapa besar minat belajar mahasiswa olahraga terhadap matakuliah gulat di Universitas islam ' 45 ' Bekasi dan faktor-faktor yang mempengaruhi minat belajar mahasiswa olahraga terhadap mata kuliah gulat Universitas islam 45 bekasi sehingga diharapkan minat belajar mahasiswa olahraga terhadap matakuliah gulat bertambah. Metode penelitian yang digunakan adalah metode survey dan data yang diperoleh menggunakan angket. Populasi dalam penelitian ini yaitu mahasiswa olahraga Universitas Islam ' 45 ' bekasi tahun ajaran 2019.. Teknik penambilan sample dilakukan menggunakan teknik total sampling, jadi 168 mahasiswaakan dijadikan sampel. Instrument yang digunakan penelitian ini adalah angket. Hasil analisa data kemudian dilakukan pengujian Hipotesis, yang menyatakan bahwa mahasiswa olahraga Universitas Islam ' 45 ' Bekasi dalam mengikuti kegiatan matakuliah gulat adalah untuk memenuhi unsur Minat yang signifikan. Hasil Penelitian menyimpulkan, bahwa unsur intrinsik memiliki peran lebih besar dengan nilai 50,86 \% dan unsur ekstrinsik sebesar 49,14\%. Unsur intrinsik yang paling berperan adalah indikator perhatian dan aktivitas dengan masing-masing prosentasinya sebesar $34 \%$, sisanya dari indikator tertarik dengan prosentase $32 \%$. Unsur ekstrinsik yang paling berperan adalah indikator dosen dengan prosentase $41 \%$, selanjutnya indikator teman $32 \%$ dan indikaror keluarga $27 \%$.
\end{abstract}

Kata kunci : gulat, minat, bakat

\begin{abstract}
The purpose of this study was to determine how much interest in learning sports students towards wrestling courses at the Islamic University of '45' Bekasi and the factors that affect students 'interest in learning sports at the University of Islam 45 wrestling courses so that it is expected that students' interest in learning sports wrestling courses increase. The research method used was a survey method and data obtained using a questionnaire. The population in this study were Islamic University sports students '45' in the 2019 school year. The sampling technique was performed using a total sampling technique, so 168 students would be sampled. The instrument used in this study was a questionnaire. The results of the data analysis were then tested by the Hypothesis, which states that the Universitas 45 'Bekasi Islamic University sports students in participating in wrestling courses were to fulfill a significant interest element. The results of the study concluded that the intrinsic element has a greater role with a value of $50.86 \%$ and an extrinsic element of $49.14 \%$. The intrinsic element that plays the most role is the indicator of attention and activity with each percentage of $34 \%$, the rest of the indicators are interested in the percentage of $32 \%$. The most important extrinsic element is the lecturer indicator with a percentage of $41 \%$, then the friend indicator is $32 \%$ and the family indicator is $27 \%$.
\end{abstract}

Keywords: wrestle, interest, talent 


\section{PENDAHULUAN}

Kondisi manusia Indonesia yang sehat jasmani dan rohani ini baru dapat dicapai apabila manusia sadar dan mau melaksanakan gerakan hidup sehat melalui pendidikan jasmani dan olahraga. Oleh karena itu gerakan memasyarakatkan olahraga dan mengolahragakan masyarakat perlu semakin gencar dilaksanankan diseluruh pelosok tanah air Indonesia. Dengan adanya gerakan tersebut, maka diharapkan akan muncul bibit-bibit olahragawan yang bermutu yang kemudian dapat dibina lebih lanjut secara khusus agar dapat menjadi bintang-bintang olahraga yang dapat mengharumkan nama bangsa dan negara Indonesia.Untuk mencapai kualitas prestasi olahraga gulat yang setinggi-tingginya perlu dilakukan pembinaan sejak dini. Salah satunya dapat dilaksanakan melalui jalur pendidikan jasmani, kesehatan dan rekreasi disekolah, dikampus atau lembaga non formal. Karena olahraga gulat ini termasuk kedalam kurikulum sebagai salah satu materi dalam matakuliah pendidikan jasmani, kesehatan dan rekreasi. Minat adalah kecenderungan yang tetap untuk memperhatikan dan mengenang beberapa kegiatan. Kegiatan yang diminati seseorang, minat juga berpengaruh terhadap belajar karena bila bahan pelajaran yang dipelajari tidak sesuai dengan minat mahasiswa atau olahraga yang tidak disukai oleh mahasiswa maka tidak akan berjalan dengan sebaik-baiknya, mengembangkan minat terhadap sesuatu pada dasarnya adalah membantu mahasiswa melihat bagaimana hubungan antara materi yang diharapkan untuk dipelajarinya dengan dirinya sebagai individu, proses tersebut menunjukan pada mahasiswa bagaimana pengetahuan atau kecakapan tertentu mempengaruhi dirinya, melayani tujuan-tujuannya, memuaskan kebutuhan-kebutuhanya. Cara meningkatkan minat mahasiswa yang paling efektif adalah dengan menggunakan minat-minat mahasiswa yang telah ada. Misalanya mahasiswa menaruh minat pada olahraga gulat sebelum mengajarkan olahraga gulat, pengajar dapat menarik perhatian mahasiswa dengan menceritakan sedikit mengenai olahraga gulat. Kemudian sedikit demi sedikit diarahkan kemateri pelajaran yang sesungguhnya. Pada dasarnya seseorang melakukan aktivitas, kegiatan atau tingkah laku selalu didasari dengan adanya minat. Semakin besar motivasi seseorang dalam melakukan aktivitas atau tingkah laku, maka semakin besar pula kemungkinan orang tersebut mencapai keberhasilan dan kesuksesan, sebaliknya semakin kecil minat seseorang dalam melakukan aktivitas atau tingkah laku, maka semakin kecil pula kemungkinan untuk meraih keberhasilan dan kesuksesan. Namun kenyataan dilapangan sangat berbeda dengan apa yang diharapkan. pada saat mengambil perkuliahan hampir semua antusias namun ketika tidak ada perkuliahan gulat yang ikut club gulat juga semakin sedikit. Hal ini yang mendorong peneliti melakukan penelitian terhadap minat belajar mahasiswa jurusan pendidikan jasmani, kesehatan dan rekreasi (PJKR) Universitas Islam " 45 " Bekasi terhadap mata kuliah gulat. Pengertian gulat pada mulanya adalah suatu kegiatan yang menggunakan tenaga dan dimungkinkan mengandung pengertian suatu perkelahian atau pertarungan yang 
sangat sengit untuk mengalahkan lawan dengan saling memukul, menendang, mencekik bahkan menggigit. Sedangkan gulat sebagai alat bela diri dilakukan manusia pada saat orang itu terjepit dan tidak memiliki senjata, satu-satunya alat bela diri adalah dengan cara bergulat. (PGSI, 1985 : 50). Setelah menjadi salah satu cabang olahraga yang dilengkapi dengan peraturan yang harus dipatuhi oleh para pesertanya, maka gulat diartikan sebagai sutau cabang olahraga yang dilakukan oleh dua orang yang saling menjatuhkan atau membanting, menguasai dan mengunci lawannya dalam keadaan terlentang dengan menggunakan teknik yang benar sehingga tidak membahayakan keselamatan lawan ( Rubianto Hadi, 2004 : 1-2 ). "Olahraga gulat terdiri dari dua gaya yang dipertandingkan yaitu Gaya Bebas (Freestyle) dan gaya Yunani-Romawi (Greeco Roman)" (Bebbi Oktara, 2010:172). Dalam olahraga gulat Gaya Bebas (Free Style), seorang pegulat diperbolehkan untuk menggunakan kaki dalam menyerang lawanya atau bertahan, menangkap kaki lawan, mengait kaki lawan dan menggunakan kaki secara aktif untuk menyerang, dengan kata lain pegulat diperbolehkan menggunakan seluruh bagian anggota badan untuk melakukan serangan. Sedangkan didalam gaya Yunani-Romawi (Greeco Roman) seorang pegulat dilarang keras untuk menyerang dibawah garis pinggang, mengait kaki lawan atau menggunakan kaki secara aktif untuk melakukan suatu gerakan. Sebelum pegulat menguasai teknik-teknik bantingan, pegulat mutlak diharuskan menguasai teknik-teknik dasar. Penguasaan teknik dasar merupakan modal utama untuk meraih prestasi. Melihat kenyataan tersebut seorang atlet gulat yang berambisi untuk berprestasi harus benar-benar menguasai teknik dasar gulat. Dengan menguasai teknik dasar, apabila diumpamakan seorang prajurit dia memiliki amunisi yang banyak dan senjata yang lengkap, sehingga memudahkan melakukan penyerangan dan pertahanan, serta dapat lebih bervariasi dalam menerapkan strategi. Adapun macam-macam teknik dasar dalam olahraga gulat menurut Rubianto Hadi (2004 : 17-23) adalah : 1) Teknik Jatuhan, 2) Teknik Posisi Bawah, 3) Teknik Serangan Kaki, 4) Teknik Susupan, 5) Teknik Tarikan 6) Teknik sambungan, 7) Teknik bantingan.Kata minat secara etimologi berasal dari bahasa inggris " interest" yang berarti kesukaan, perhatian (kecenderungan hati pada sesuatu), keinginan. Jadi dalam proses belajar siswa harus mempunyai minat atau kesukaan untuk mengikuti kegiatan belajar yang berlangsung, karena dengan adanya minat akan mendorong siswa untuk menunjukan perhatian, aktivitasnya dan partisipasinya dalam mengikuti belajar yang berlangsung. Menurut Ahmadi (2009: 148) "Minat adalah sikap jiwa orang seorang termasuk ketiga fungsi jiwanya (kognisi, konasi, dan emosi), yang tertuju pada sesuatu dan dalam hubungan itu unsur perasaan yang kuat" Menurut Slameto (2003:180), "minat adalah kecenderungan yang tetap untuk memperhatikan dan mengenang beberapa kegiatan". Sedangkan menurut Djaali (2008: 121) "minat adalah rasa lebih suka dan rasa ketertarikan pada suatu hal atau aktivitas, tanpa ada yang menyuruh". Berdasarkan pendapat para ahli diatas 
dapat disimpulkan bahwa pengertian minat adalah adanya rasa ketertarikan, perhatian dan aktivitas lebih yang dimiliki seseorang terhadap sesuatu hal, tanpa adanya paksaan. Minat belajar adalah ketertarikan seseorang yang dapat menimbulkan perubahan pengetahuan, keterampilan dan tingkah laku. Dalam minat belajar memiliki beberapa ciri-ciri. Menurut Elizabeth Hurlock (dalam Susanto, 2013: 62) menyebutkan ada tujuh ciri minat belajar sebagai berikut: 1) Minat tumbuh bersamaan dengan perkembangan fisik dan mental, 2)Minat tergantung pada kegiatan belajar, 3)Perkembangan minat mungkin terbatas, 4) Minat tergantung pada kesempatan belajar, 5) minat berbobot emosional, 6) Minat dipengaruhi oleh budaya dan 7) Minat berbobot egoisentris, artinya jika seseorang senang terhadap sesuatu, maka akan timbul hasrat untuk memilikinya.,Menurut Siti Rahayu Haditono (1998:189) menjelaskan bahwa ada 2 faktor yang mempengaruhi minat seseorang yaitu : “(1) Faktor dari dalam (intrinsik) yaitu sifat pembawaan dan (2) Faktor dari luar (ekstrinsik), diantaranya keluarga, sekolah dan masyarakat sekitar.

Tabel 1 Kisi-Kisi Uji Coba Angket

\begin{tabular}{|c|l|l|l|}
\hline Variabel & \multicolumn{1}{c}{$\begin{array}{c}\text { Sub } \\
\text { Variabel }\end{array}$} & Indikator & $\begin{array}{c}\text { Jumlah } \\
\text { No Soal }\end{array}$ \\
\hline \multirow{2}{*}{$\begin{array}{c}\text { Minat } \\
\text { terhadap } \\
\text { matakuli } \\
\text { ah gulat }\end{array}$} & $\begin{array}{l}\text { Minat } \\
\text { Intrinsik }\end{array}$ & Tertarik & \\
\cline { 3 - 4 } & & Perhatian & $7-12$ \\
\cline { 3 - 4 } & Ekstrinsik & Aktivitas & $13-18$ \\
\cline { 3 - 4 } & & Dosen & $19-24$ \\
\cline { 3 - 4 } & & Teman & $25-30$ \\
\hline
\end{tabular}

\section{BAHAN DAN METODE}

Dalam penelitian ini penulis menggunakan metode deskriptif.
Menurut Arikunto (2010:3) menjelaskan bahwa "Penelitian Deskriptif adalah penelitian yang dimaksudkan untuk menyelidiki keadaan kondisi atau hal lain-lain yang sudah disebutkan yang hasilnya dipaparkan dalam bentuk laporan penelitian". Metode ini digunakan penulis didasarkan pada permasalahan yang diajukan untuk diteliti dimana dalam penelitian ini diharapkan dapat mengungkapkan "Minat Belajar Mahasiswa Olahraga terhadap Matakuliah Gulat di Universitas Islam '45' Bekasi'. Populasi adalah sekelompok subyek yang akan diteliti, seperti dijelaskan oleh Arikunto (2010:123). Berdasarkan pendapat tersebut serta rumusan masalah, maka penulis menetapkan populasi dalam penelitian ini adalah mahasiswa olahraga yang sedang mengambil matakuliah gulat tahun ajaran 2019/2020 di Universitas Islam 45 Bekasi sebanyak 168 orang. sedangkan teknik pengambilan sampel dalam penelitian ini adalah total sampling, maksudnya semua mahasiswa olahraga tahun ajaran 2019/2020 yang mengambil matakuliah gulat dijadikan sampel. Tempat penelitian di jl. Cut mutia no. 83 Universitas Islam 45 Bekasi. Desain penelitian menurut Moh.Nazir (2003:11) adalah: " Semua proses yang diperlukan dalam perencanaan dan pelaksanaan penelitian, mulai tahap persiapan sampai tahap penyusunan laporan ". Maka dari itu agar proses penelitian ini terarah, rinci dan sistematis. Penulis membuat desain penelitian, sebagai berikut ; popilasi - sampel - uji coba nagket - penyebaran angket - analisis data - kesimpulan. Untuk mengumpulkan data yang akan diolah dan dianalisa dipergunakan instrument 
penelitian. Sesuai dengan metode yang digunakan instrumen untuk Penelitian ini berupa Angket yang ditujukan kepada mahasiswa yang sedang mengambil matakuliah gulat di Universitas Islam ' 45 ' Bekasi yang menjadi sample dalam penelitian ini. Menurut Sugiyono (2011:81) Skala Likert digunakan untuk mengukur sikap, pendapat dan persepsi seseorang atau sekelompok orang tertentu. Dengan Skala Likert maka variabel yang akan diukur dijabarkan menjadi indikator variabel.

Tabel 1 Kisi-Kisi Uji Coba Angket

\begin{tabular}{|c|c|c|c|}
\hline Variabel & $\begin{array}{c}\text { Sub } \\
\text { Variabel }\end{array}$ & Indikator & $\begin{array}{c}\text { Jumlah } \\
\text { No Soal }\end{array}$ \\
\hline \multirow{6}{*}{$\begin{array}{c}\text { Minat } \\
\text { terhadap } \\
\text { matakuliah } \\
\text { gulat }\end{array}$} & \multirow{3}{*}{$\begin{array}{l}\text { Minat } \\
\text { Intrinsik }\end{array}$} & Tertarik & $1-6$ \\
\hline & & Perhatian & $7-12$ \\
\hline & & Aktivitas & $13-18$ \\
\hline & \multirow{3}{*}{$\begin{array}{l}\text { Minat } \\
\text { Ekstrinsik }\end{array}$} & Dosen & $19-24$ \\
\hline & & Teman & $25-30$ \\
\hline & & Keluarga & $31-36$ \\
\hline
\end{tabular}

\section{HASIL DAN PEMBAHASAN}

Sebelum dilakukan pengolahan data maka angket yang telah disusun harus diuji coba untuk mengukur tingkat validitas dan reliabilitas dari setiap butir pertanyaan-pertanyaan. Dari uji coba angket akan diperoleh sebuah angket yang memenuhi syarat dan dapat digunakan sebagai pengumpulan data dalam penelitian ini. Uji coba angket ini dilakukan terhadap 30 mahasiswa olahraga yang sudah menggambil matakuliah gulat. Perhitungan analisis data menggunakan IBM SPSS Statistic 21.

Hasil perhitungan uji coba angket dari 36 butir soal semuanya dinyatakan valid karena r-hitung lebih besar dari $\mathrm{r}$ tabel (361). Dengan ini ada 36 pertanyaan yang akan dijadikan pengumpulan data.

Teknik yang digunakan dalam uji normalitas adalah uji KolmogorovSmirnov. Pada uji normalitas data minat belajar matakuliah gulat nilai sebesar 2.549, karena p value (sig.) > 0.05 maka dapat disimpulkan bahwa minat belajar matakuliah gulat diambil dari sampel yang berdistribusi normal.

Selanjutnya, peneliti melakukan analisis minat belajar matakuliah gulat mahasiswa olahraga secara keseluruhan yang dapat dilihat pada tabel 3. berikut ini.

Tabel 2. Analisis minat belajar matakuliah gulat mahasiswa olahraga

\begin{tabular}{|c|c|c|c|c|c|}
\hline No & $\begin{array}{c}\text { Perangkat } \\
\text { Data }\end{array}$ & $\Sigma \mathrm{X}$ & $\bar{X}$ & $S$ & $\%$ \\
\hline 1 & $\begin{array}{l}\text { Minat } \\
\text { intrinsik }\end{array}$ & 9747 & 58.02 & 2.884 & 50.86 \\
\hline 2 & $\begin{array}{l}\text { Minat } \\
\text { ekstrinsik }\end{array}$ & 9419 & 56.07 & 3.080 & 49.14 \\
\hline
\end{tabular}
diperoleh bahwa dari sub variabel minat intrinsik jumlah nilai $\mathrm{x}$ sebesar 9747, nilai rata-rata 258.02 dan simpangan baku 2.884 dengan prosentase $50.86 \%$. Sedangkan untuk sub variabel minat eksternal jumlah nilai $x$ sebesar 9419, nilai rata-rata 56.07 dan simpangan baku 3.080 dengan prosentase $49.14 \%$. Selanjutnya, peneliti melakukan analisis minat belajar matakuliah gulat mahasiswa olahraga berdasarkan indikator intrinsik yang dapat dilihat pada tabel 3. berikut ini.

Tabel. 3 Analisis minat belajar matakuliah gulat mahasiswa olahraga berdasarkan indikator minat intrinsik

\begin{tabular}{llrr}
\hline No & Indikator & Jumlah & Prosentase \\
\hline 1 & Tertarik & 3306 & $34 \%$ \\
\hline 2 & Perhatian & 3284 & $34 \%$ \\
\hline 3 & Aktivitas & 3157 & $32 \%$ \\
\hline & Jumlah & 9747 & $100 \%$ \\
\hline & Berdasarkan & tabel diatas & dapat
\end{tabular}
dilihat kontribusi dari tiga indikator minat intrinsik, ternyata pengaruh dari tertarik memiliki pengaruh sebesar 34 
$\%$, pengaruh indikator perhatian terhadap minat intrinsik sebesar $34 \%$ dan indikator aktivitas memiliki pengaruh $32 \%$ terhadap minat belajar matakuliah gulat pada mahasiswa olahraga. Selanjutnya, peneliti melakukan analisis minat belajar matakuliah gulat mahasiswa olahraga berdasarkan indikator ekstrinsik yang dapat dilihat pada tabel 4. berikut ini.

Tabel. 4 Analisis minat belajar matakuliah gulat mahasiswa olahraga berdasarkan indikator minat ekstrinsik

\begin{tabular}{llrr}
\hline No & Indikator & Jumlah & Prosentase \\
\hline 1 & Dosen & 3833 & $41 \%$ \\
\hline 2 & Teman & 3040 & $32 \%$ \\
\hline 3 & Keluarga & 2546 & $27 \%$ \\
\hline & Jumlah & 9419 & $100 \%$ \\
\hline
\end{tabular}

Berdasarkan tabel diatas dapat dilihat kontribusi dari tiga indikator minat ektrinsik, ternyata dosen memiliki pengaruh sebesar $41 \%$, pengaruh indikator teman terhadap minat intrinsik sebesar $32 \%$ dan indikator keluarga memiliki pengaruh $27 \%$ terhadap minat belajar matakuliah gulat pada mahasiswa olahraga. Perhitungan hasil pengujian validitas tiap item soal, dari 36 item soal dinyatakan valid semua r-hitung lebih besar dari r-tabel, karena ( $\mathrm{N}$ ) uji coba 30 responden, maka r-tabelnya 0,361 pada taraf signifikan 5\%. Reliabilitas diperoleh nilai sebesar " $r$ " alfa $=0,961$ maka instrumen dinyatakan reliabel, oleh sebab itu kuesioner / instrument layak disebarkan kesampel sesungguhnya sebanyak 168 orang. Setelah menganalisis data minat belajar matakuliah gulat mahasiswa olahraga, minta intrinsik memiliki pengaruh $50.86 \%$ dan minat ekstrinsik memiliki pengaruh $49.14 \%$. Sub variabel intrinsik dipengaruhi oleh tiga indikator yaitu tertarik $34 \%$, perhatian $34 \%$ dan aktivitas $32 \%$. Sedangkan sub variabel ekstrinsik dipengaruhi oleh tiga indikator yaitu dosen $41 \%$, teman $32 \%$ dan keluarga $27 \%$.

\section{KESIMPULAN DAN SARAN}

Berdasarkan pemaparan di atas, dapat disimpulkan bahwa minat belajar mahasiswa olahraga terhadap matakuliah gulat dilihat dari variabel intrinsik berpengaruh sebesar $50.86 \%$ dan variabel ekstrinsik sebesar $49.14 \%$. minta intrinsik dipengaruhi indikator tertarik $34 \%$, perhatian $34 \%$ dan aktivitas $32 \%$. Sedangkan minat ekstrinsik dipengaruhi oleh indikator dosen sebesar $41 \%$, teman $32 \%$ dan keluarga $27 \%$. Minat belajar gulat sangat dibutuhkan bagi mahasiswa olahraga, supaya olahraga gulat bisa makin memasyarakat, tercipata atlet dan pelatih berprestasi. Oleh sebab itu, disarankan kepada para pimpinan baik dilingkup jurusan, fakultas maupun universitas agar memperhatikan sarana dan prasarana perkuliahan gulat agar minat mahasiswa terhadap olahraga gulat bisa terus disalurkan serta diperdalam lagi di unit kegiatan mahasiswa.

\section{DAFTAR PUSTAKA}

Abu Ahmadi. 2009. Psikologi Umum. Jakarta : Rieka Cipta

Ahmad Susanto. 2013. Teori Belajar dan Pembelajaran di Sekolah Dasar. Jakarta : Kencana Prenada Media Group

Arikunto. Suharsimi. 2010. Prosedur Penelitian. Rineka Cipta : Jakarta

Bebbi Oktara. 2010. Aktivitas Ketangkasan dan Beladiri. Depok : Binamuda.

Djali. 2008. Psikologi Pendidikan. Jakarta : Bumi Aksara. 
Moh. Nazir. 2013. Metode Penelitian. Bogor, Ghalia Indonesia.

PGSI. 1985. Seperempat Abad Gulat di Indonesia, Jakarta : Persatuan Gulat Seluruh Indonesia Cabang Jakarta Barat.

Siti Rahayu Haditono. 1998. Psikologi Perkembangan. Yogyakarta : Psikologi UGM

Slameto. 2003. Belajar dan Faktor Faktor Yang Mempengaruhinya, Jakarta: PT Rineka Cipta.

Sugiyono. 2011. Metode Penelitian Kuantitatif, Kualitatif dan $R \& D$. Bandung : Alfabeta.

Rubianto Hadi. 2004. Buku Ajar Gulat, Semarang : FIK UNNES 